\title{
Endoscopic ultrasound-guided trans-duodenal fine-needle biopsy of a small renal mass: case report and review of the literature
}

\author{
Justin Kwong ${ }^{1}$ (D), Gary May ${ }^{2}$ and Michael Ordon ${ }^{*}$
}

\begin{abstract}
Background: The incidental detection of small renal masses (SRMs) is increasing and biopsy to obtain pathological diagnosis is increasingly proposed as a diagnostic tool to guide further management. Renal mass biopsies are traditionally performed via a percutaneous approach. However, this is not always feasible due to anatomical limitations. A rarely reported alternative biopsy approach for SRMs is endoscopic ultrasound (EUS)-guided fine-needle biopsy (FNB). Herein, we describe a case of EUS-guided trans-duodenal FNB for a SRM that was not amenable to standard percutaneous biopsy.

Case presentation: A 48-year-old man was incidentally found to have a right-sided SRM measuring $2.9 \times 2.2 \times 2.4 \mathrm{~cm}$ during evaluation for a hernia. It was anterior, interpolar, completely endophytic and near the renal hilum. The tumor was not amenable to traditional percutaneous biopsy due to its anterior location. However, the renal mass was in close proximity to the descending duodenum and so it was felt that an EUS-guided trans-duodenal FNB would be feasible. The procedure was successful without any complications. The specimen adequacy was satisfactory for evaluation and consistent with renal papillary carcinoma with WHO/ISUP grade 3 nuclear changes.
\end{abstract}

Conclusion: Our case report demonstrated that EUS-guided trans-duodenal FNB was a safe and feasible approach to obtaining biopsy tissue diagnosis of a SRM that was not amenable to percutaneous biopsy.

Keywords: Case report, Renal, Biopsy, Endoscopic, Trans-duodenal

\section{Background}

Incidental detection of small renal masses (SRMs) has been increasing and attributed to the increased utilization of imaging including computed tomography (CT) and ultrasound (US) for unrelated reasons [1]. In general, there are two methods of tissue sampling renal masses: fine-needle aspiration (FNA) and biopsy. FNA is conducted via a thin needle inserted into the tissue mass

\footnotetext{
*Correspondence: Michael.Ordon@unityhealth.to

${ }^{1}$ Division of Urology, Department of Surgery, St. Michael's Hospital, University of Toronto, 61 Queen St. E., Ste. 9-103, Toronto, ON M5C 2T2, Canada

Full list of author information is available at the end of the article
}

to aspirate cells without preservation of the histologic architecture of tissue cells. A biopsy involves sampling of a portion of the tissue itself and is associated with a higher diagnostic rate as well as allowing for more accurate histologic assessment [2]. Biopsy is being increasingly proposed as a diagnostic tool to guide informed management of SRMs [3]. Percutaneous biopsy is the standard technique to obtain a pathological diagnosis of SRMs. However, this approach may not be feasible in anatomically unfavorable lesions, such as anterior or central renal masses, obese patients, high sitting kidneys and long skin-to-tumor distances. An alternative and rarely reported biopsy approach for SRMs is endoscopic 
ultrasound (EUS)-guided fine-needle biopsy (FNB). Herein, we report a case of EUS-guided trans-duodenal FNB for an anterior, interpolar, completely endophytic SRM that was not amenable to a standard percutaneous renal biopsy.

\section{Case presentation}

A 48-year-old man was incidentally found to have small right renal mass on contrast-enhanced CT scan after evaluation for a hernia. The right renal mass measured $2.9 \times 2.2 \times 2.4 \mathrm{~cm}$ (Fig. 1). It was anterior, interpolar, endophytic and near the renal hilum. There was no intraabdominal lymphadenopathy or metastatic disease. He was asymptomatic. His past medical history includes hyperlipidemia and stable human immunodeficiency virus with no prior abdominal surgery. Social and family history was non-contributory. On physical examination, he appeared healthy and his abdomen was unremarkable with no tenderness or palpable masses. After informed discussion, the patient strongly preferred an attempt at renal mass biopsy to obtain a histopathological diagnosis prior to considering surgical intervention. Given its anterior location, the renal mass was not amenable to percutaneous biopsy. However, the renal mass was in close proximity to the descending duodenum and it was felt that an EUS-guided trans-duodenal FNB would be feasible. This procedure was successful without any complications. The specimen adequacy was satisfactory for evaluation, and the appearance and immunohistochemical profile were consistent with renal papillary carcinoma with WHO/ISUP grade 3 nuclear changes. Immunohistochemical staining of the tumor cells were positive for CK7, racemase and vimentin. After a detailed discussion of management options, the patient proceeded with a right robotic-assisted laparoscopic partial nephrectomy with intraoperative ultrasound. Intraoperatively, the duodenum was just slightly adherent to the kidney, likely as a result of the previous FNB. The duodenum was easily and safely kocherized. There were no intraoperative or postoperative complications. In follow-up, pathology revealed pT1a papillary type 2 renal cell carcinoma (RCC), WHO/ ISUP grade $3 / 4$, with negative margins.

\section{Discussion}

EUS-guided FNB is a rarely reported technique to obtain tissue diagnosis of a renal mass. In our review of literature, there has only been one case report describing this technique [4]. They performed their biopsy with a $22 \mathrm{G}$ cutting needle specifically designed to collect cores with larger tissue samples. Compared to aspiration, biopsy allows for sampling of a larger amount of tissue, preserves tissue histologic architecture and is associated with a higher diagnostic rate and more accurate histologic assessment $[5,6]$. A meta-analysis comparing renal mass FNA with conventional percutaneous biopsy has shown biopsy to have superior sensitivity and specificity [7].

EUS-guided FNA of a renal mass was first described by Farrel and Brugge in 2002 [8]. They published a case report of a 71-year-old man with a $9 \mathrm{~cm}$ right mid-pole renal mass where trans-duodenal FNA cytology revealed malignant cells consistent with RCC. In our literature review, there have since been three case series and five case reports describing EUS-guided approaches to sample renal mass pathology [2, 4, 9-14]. In the present case report, an FNB as opposed to an FNA was performed allowing for an intact core to be sampled revealing the true architecture of the tissue, which can sometimes be necessary to make a pathologic diagnosis.

The largest study to date was a case series by Dewitt et al. including fifteen EUS-guided renal FNAs from six tertiary hospitals in the USA [11]. In their study, the sensitivity of EUS-FNA for malignancy was 83\%, comparable to the sensitivity of CT-guided biopsy (80 to

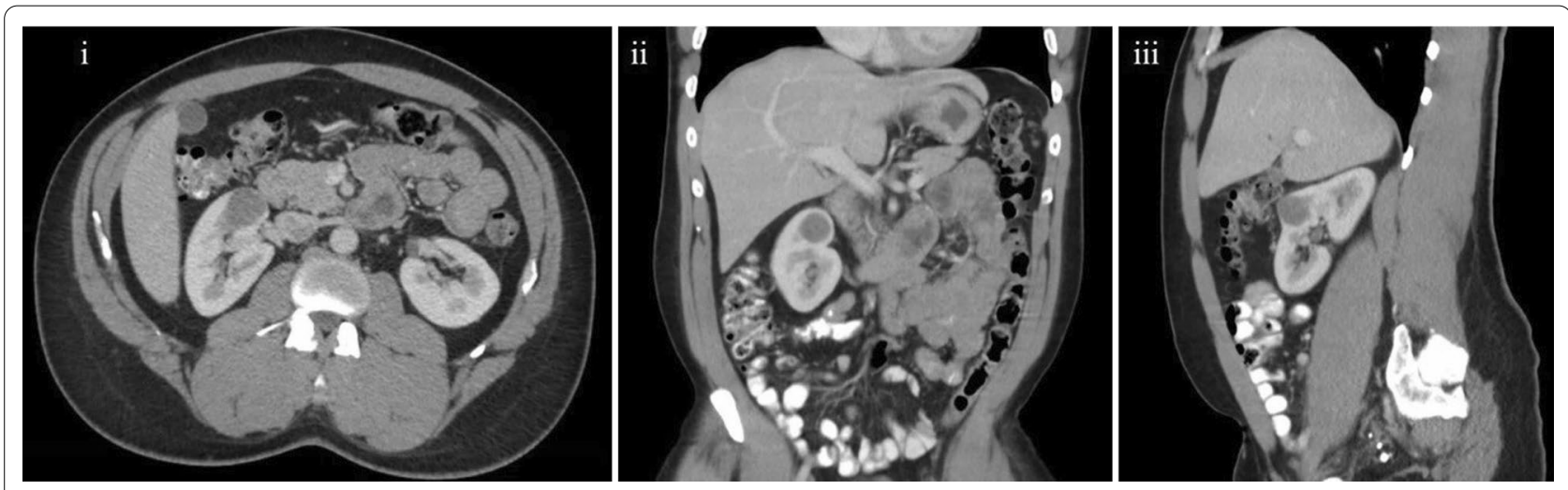

Fig. 1 CT images of right renal mass: i selected axial image; ii selected coronal image; iii selected sagittal image 
92\%) [15]. There was a single false cytologic diagnosis of oncocytoma in a patient who went on to have surgically confirmed RCC. There was also a single non-diagnostic biopsy. They encountered no complications. The authors felt that EUS-guided FNA was safe and feasible. Only two out of fifteen patients in the series were initially referred specifically for EUS-guided renal biopsy suggesting that referring physicians may be unaware of the potential use of EUS in evaluating renal lesions. Additionally, nine of fifteen patients underwent concomitant extrarenal biopsies including stomach, liver, mediastinal lymph node, pancreas, spleen and adrenal, suggesting that EUS allows for biopsy of multiple anatomical sites during a single procedure, and as such, EUS may be attractive in cases where there is the desire to biopsy different anatomical sites during a single procedure.

With respect to EUS biopsy technique, it has been described that the right kidney may be approached from the second portion of the duodenum with the EUS transducer rotated laterally [4]. This was the approach used in our case. The left kidney may be approached from the stomach body with the EUS transducer posterolateral [4]. Given the relative location of the gastrointestinal tract to the kidneys, EUS-guided biopsies are most applicable to central anterior renal masses $[4,11]$. In contrast, posterior renal masses are challenging to access endoscopically; however, these lesions are often easily accessible for percutaneous US or CT-guided biopsy [4, 11, 13].

There have been no complications following EUSguided FNA for renal masses reported in the literature. This may be a result of publication and selection bias. Complications following EUS-guided FNA in general have been reported to be between 1 and 6\% [2]. Tracheal suction $(5 \%)$, hemorrhage $(1 \%)$, vomiting $(0.3 \%)$, aspiration (0.3\%) and death (less than $0.06 \%$ ) have been described as EUS complications [2]. Tumor seeding is rare [16]. Despite the limited literature, EUS-guided FNA for renal masses is presumably safe. In our study of EUSguided FNB, we did not experience any complications.

Although EUS-guided biopsy in our case was used as a first-line technique, there may be utility for EUS-guided biopsy as a second-line technique in cases of failed percutaneous renal biopsy. Law et al. describe a case in which CT-guided percutaneous biopsy of a $3.8 \mathrm{~cm}$ anterior, lower pole left renal mass in a 68-year-old woman was performed with difficulty due to intervening bowel at two optimal percutaneous sites and subsequent percutaneous histology came back as non-diagnostic [13]. As a second-line approach, EUS-FNA was performed successfully and histology was diagnostic for RCC. Compared to traditional percutaneous renal biopsy, which is performed through a posterior approach, EUS-guided FNB may allow better access to the kidney in patients with obesity, long skin-to-tumor distance, intervening bowel and high and anterior renal masses, while similarly maintaining good tissue architecture [4].

\section{Conclusion}

Our case report demonstrated that EUS-guided transduodenal FNB was a safe and feasible approach to obtaining biopsy tissue diagnosis of a SRM that was not amenable to percutaneous biopsy.

\section{Abbreviations \\ SRM: Small renal mass; EUS: Endoscopic ultrasound; RCC: Renal cell carcinoma; FNA: Fine-needle aspiration; FNB: Fine-needle biopsy; CT: Computed tomogra- phy; US: Ultrasound. \\ Acknowledgements \\ Not applicable. \\ Authors' contributions \\ JK was a major contributor in writing the manuscript. All authors (JK, GM and $\mathrm{MO}$ ) read and approved the final manuscript. \\ Funding \\ There are no sources of funding.}

Availability of data and material

Data sharing is not applicable to this article as no datasets were generated or analyzed during the current study.

\section{Declarations}

Ethics approval and consent to participate

Not applicable.

\section{Consent for publication}

Written informed consent was obtained from the patient for publication of this case report and accompanying images.

\section{Competing interests}

The authors declare that they have no competing interests.

\section{Author details}

'Division of Urology, Department of Surgery, St. Michael's Hospital, University of Toronto, 61 Queen St. E., Ste. 9-103, Toronto, ON M5C 2T2, Canada. ${ }^{2}$ Division of Gastroenterology, Department of Medicine, St. Michael's Hospital, University of Toronto, Toronto, Canada.

Received: 15 July 2021 Accepted: 17 October 2021

Published online: 30 October 2021

References

1. Znaor A, Lortet-Tieulent J, Laversanne M (2015) International variations and trends in renal cell carcinoma incidence and mortality. Eur Urol 67:519-530

2. Moura RN, Lopes RI, Srougi M et al (2014) Initial experience with endoscopic ultrasound-guided fine needle aspiration of renal masses: indications, applications and limitations. Arq Gastroenterol 51:337-340

3. Burruni R, Lhermitte B, Cerantola Y et al (2016) The role of renal biopsy in small renal masses. CUAJ 10:28-33

4. Piccirilli A, Romantini F, Saldutto P et al (2020) Endoscopic ultrasoundguided trans-duodenal biopsy of a renal mass: Case report and literature review. Urol Case Rep 31:1-3 
5. Tsivian M, Rapersaud EN, del Pailar Laguna Pes M et al (2014) Small renal mass biopsy - how, what and when: report from an international consensus panel. BJU Int 113:854-863

6. Moschetta M, Telegrafo M, Carluccio DA (2014) Comparison between fine needle aspiration cytology (FNAC) and core needle biopsy (CNB) in the diagnosis of breast lesions. G Chir 35:171-176

7. Marconi L, Dabestani S, Lam TB et al (2016) Systematic review and metaanalysis of diagnostic accuracy of percutaneous renal tumor biopsy. Eur Urol 69:660-673

8. Farrell JJ, Brugge WR (2002) EUS-guided fine-needle aspiration of a renal mass: an alternative method for diagnosis of malignancy. Gastrointest Endosc 56:450-452

9. Marco DF, Christian G, Giovanni M et al (2020) Endoscopic ultrasoundguided fine needle aspiration of small renal masses in selected patients: case reports. J Urol Neph 2:213-216

10. Artifon ELA, Lopes RI, Kumar A et al (2008) Endoscopic ultrasound facilitates histological diagnosis of renal cell cancer. J Endourol 22:2447-2450

11. Dewitt J, Gress F, Levy M et al (2009) EUS-guided FNA aspiration of kidney masses: a multicenter U.S. experience. Gastrintest Endosc 70:573-578
12. Ha J, Kim D, Kim H et al (2020) Endoscopic ultrasound-guided fine needle aspiration biopsy of a renal mass. Korean J Helicobacter Up Gastrointest Res 21:93-95

13. Law R, Wobker S, Grimm IS et al (2015) Endoscopic ultrasonographyguided fine needle aspiration of kidney masses. Gastroenterology 148:1282-1283

14. Bazaga S, Tejedor J, Gallardo MA et al (2020) EUS guided fine needle aspiration of renal and adrenal lesions. Single center retrospective analysis. Endoscopy $52:$ : $2-5$

15. Gill IS, Aron M, Gervais DA et al (2010) Clinical practice. Small renal mass. N Engl J Med 352:624-634

16. Doi S, Yasuda I, Iwashita T et al (2008) Needle tract implantation on the esophageal wall after EUS-guided FNA of metastatic mediastinal lymphadenopathy. Gastrointest Endosc 67:988-990

\section{Publisher's Note}

Springer Nature remains neutral with regard to jurisdictional claims in published maps and institutional affiliations.

\section{Submit your manuscript to a SpringerOpen ${ }^{\circ}$ journal and benefit from:}

- Convenient online submission

- Rigorous peer review

- Open access: articles freely available online

- High visibility within the field

- Retaining the copyright to your article

Submit your next manuscript at $\boldsymbol{\nabla}$ springeropen.com 